\title{
学校社会工作在教育管理主义背景下引入学生管理 的必要性和可行性
}

\section{The necessity and feasibility of introducing student management into school social work in the context of educational managerialism \\ Taking the fall of Miu Kexin as an example}

\author{
方欣怡 \\ Xinyi Fang \\ 南京理工大学 中国・江苏 南京 210000
}

Nanjing University of Science and Technology, Nanjing, Jiangsu, 210000, China

\begin{abstract}
摘要: 当前许多学校推崇以管理主义为主的管理模式,而以“效率”为核心追求的管理主义随着实践地不断深入,其种种弊 端显露无疑。从缪可馨陸楼事件可以看出教育管理主义对学生成长成才的危害, 不仅从根本上扼杀了学生的主观能动性, 同 时也损害了学生的自主创新能力。为解决学校管理这一困境,引入学校社会工作的理论与方法具有一定的必要性和可行性。
\end{abstract}

\begin{abstract}
At present, many schools advocate the managerialism-based management model, the "efficiency" as the core of the pursuit of managerialism with the deepening of practice, its shortcomings are no doubt exposed. From the case of Miu Kexin falling from a building, we can see that the damage of educational managerialism to students'growth and development not only kills students'subjective initiative, but also damages students'independent innovation ability. In order to solve the dilemma of school management, it is necessary and feasible to introduce the theory and method of school social work.
\end{abstract}

关键词教育管理主义;学校社会工作;创新能力; 个性化

keywords : educational managerialism; School Social Work; innovative ability; individualization

DOI : $10.36012 /$ sde. v3i2. 2953

\section{1 教育管理主义的倾向和表现}

\section{1 管理主义的具体含义}

作为新管理主义的一种形式,管理主义也被称为新公共 管理。最初管理主义在公共行政管理领域和企业管理领域 被广泛应用。其核心是“服从”, 即组织内所有成员工作和行 为都必须按照一定的规范。管理主义之所以备受管理者青 睐, 是因为在管理主义的指导下, 管理工作能够顺利开展, 并 且工作效率和管理效率也大大提升。近几年同时也出现管 理主义运用在在教育工作领域中的情况。

\section{2 教育管理主义的具体含义}

绝对服从是教育管理主义的核心, 教育管理者希望学生 能够有着非常高的配合度。教育管理主义要不断的强化教 育工作过程中学生的统一性和服从性。从很多方面来看, 教

\section{育管理主义都非常的盛行。}

教育管理主义主要体现的是没有因材施教,忽视了学生 的个性差异,一切教育管理经验都服从于管理的方式 ${ }^{[1]}$ 。分 班、分级教学的确有益于不同水平的学生能够跟上正常的教 学进度, 但仅仅这样是不够的的, 大部分学校在教育管理问 题上,却将教育思想执行和规划都控制在一定范围内。这样 的现象存在与众多学校中。学生们必须按照统一的标准去 学习, 学习方法、课程答案都必须完全一致, 不允许有任何偏 差, 而这样的统一的管理模式和教学模式正在磨灭着学生们 的个性差异。这使得学生们逐渐趋同, 就像是学校这一大工 厂里批量生产的螺丝钉。

当然教育管理主义也存在着不可忽视的优势。教育管 理主义这种教育模式在教学过程中有着非常好的教学管理

【作者简介】方欣怡(2000 )女, 汉, 福建三明人,南京理工大学, 本科生, 从事学校社会工作、青少年社会工作、社会政策等研究。 
效率。利用一定的教育实践, 能够培养和教育更多的学生。 同时教育管理主义在教育工作的进行中, 能够有效的节约教 师资源, 缓解我国的教育工作者紧缺的情况。

但同时管理主义在教学过程中也造成了非常严重的后 果。以我国的传统教育作为典型例子, 封闭的教育模式作为 常用教学管理手段切断了学生们与学校外的关联, 阻碍了校 外环境对于学生的影响, 同时也阻碍了学生们对学校以外的 环境的适应。不仅如此, 即使在校内, 学生与教育工作者在 同一的教育管理模式下缺乏良好的交流和沟通, 这就造成了 学生的学习问题、心理问题不能够尽早地被发现, 还影响了 学生的创新能力和交流能力的提升。

\section{2 案例分析}

在 2020 年 6 月 4 日, 常州市一名五年级的学生因为被 语文老师过度修改语文作文并掌掴, 在课间从四楼坠楼身 亡。我想将此次事件看作是教育管理主义的恶果之一。在 中国, 学生们从小就被老师要求做一个“乘学生”, 要服从老 师、学校的安排。穿什么、学什么、怎么学都有一套标准的模 板和评判标准, 学生一旦偏离标准答案, 就会被判定为错误。 在一个大的集体里,保障公平不是第一位,维持稳定才是第 一位。

而这名学生和她的家长就是“破坏稳定” 的人。在她老 师开设校外培训班的时候, 她没有参加并被老师针对; 她写 作文抒发真情实感, 被老师说负能量、三观不正。这名同学 与其他“好学生”不一致的行为影响了老师对班级的管理。 这也就反映出在部分学校老师先是管理者,再是教育者。

\section{3 将学校社会工作理论与方法引入学生管 理的必要性和可行性}

\section{1 将学校社会工作理论与方法引入学校学生管 理的必要性}

3.1 .1 应对剧烈社会变迁的迫切需要

一方面,社会高度发展、信息更迭变换,学生群体出现的 诸多变迁使得学校学生管理出现诸多新情况和新问题, 变革 传统的工作思路和工作方法, 综合分析家庭、社会等诸多环 境因素, 全面考虑影响学生成长成才的心理因素, 突破障碍, 是学校应对当前管理困境的必由之路, 只有这样才能系统解 决学生管理中的新问题和新挑战。

\section{1 .2 培育创新型人才的战略需要}

21 世纪初我国就提出了素质教育培养创新型人才的要 求, 这是转型创新型国家对学校提出的战略目标。对于培养 创新新人才, 传统教育模式稍显乏力。在挖掘学生创造潜力 和思维能力等方面教育管理主义体现出明显不足。而在这 方面有明显优势的学校社会工作, 秉持着“助人自助” 的工作
理念, 学校社会工作致力于培养发掘学生潜力, 提升学生解 决问题的能力, 而不是把学生当做“问题”。

\section{1 .3 满足学生个性化成长需求的现实需要}

当代学生作为新时代未来的接班人, 有着与时代相通的 特性,勇于创新,敢于挑战是他们的时代特征。传统教育管 理主义模式的教条般的说教和统一的行政管理模式抑制了 他们个性化的发展需要。当学生面对不同困境,不同需求 时,学校社会工作都能针对学生不同的特征,运用其专门的 理论和工作方法, 从根本上帮助学生解决问题。

\section{2 将学校社会工作理论与方法引入学校学生管 理的可能性}

3.2.1 从服务手段的选择上看, 学校社会工作除了关注学 生本身和学校外,还会统筹考虑 “家庭一学校一社会” 的联动

针对学生遇到的困境,传统学校学生管理者更多关注问 题本身的社会影响,为尽快消除社会影响,维持校园稳定和 谐的环境和社会声誉,管理者会集中调配资源,学校快速的 平息事件的影响 ${ }^{[2]}$ 。而学生本身的问题反而不那么受到 重视。

“人在情境中” 的假设,通过重构是学校社会工作的重要 理论,将家庭、社会、学校进行良性互动, 从“情境” 中全面考 虑学生们面临的困境,通过改善外部情境, 推动服务对象发 生转变 ${ }^{[3]}$ 。同时, 学校社会工作还坚持运用专业理论和“案 主自决” 的价值观念, 挖掘服务对象自身优势资源, 实现自我 成长与转变。

3.2.2 从服务目标上看, 除了解决学生面临的困境, 学校社 会工作更注重增强服务对象发掘资源和改变困境的能力

学校教育管理目标与学校社会工作相一致的地方就是 帮助学生解决其面临的困境。追求高效是传统学校学生管 理的工作倾向, 终极目标仅是解决当前学生面临的困境和给 学校带来的影响,出于这个目的,学校往往会利用外部资源 来解决困境, 从这个角度来看, 教育管理主义扮演着资源提 供者和问题解决者两个角色。而学校社会工作的目的不仅 如此,在面对困境学生时,社会工作者往往会在 “助人自助” 的工作价值理念下转变视角,在与学生交流的过程中发挥学 生的能动性, 帮助学生工疏导问题的成因, 共同探索如何解 决问题, 与学校不同, 学校社会工作者扮演引导者和支持者。

\section{参考文献}

［1］周文杰. 一流本科教育中的管理主义 $[\mathrm{J}]$. 北京教育 (高教), $2020(06): 15-19$.

２］邢政权,赵忠. 管理主义对学生评教的负面影响及其消解 [ J ] . 教育评论, 2017(02):61-64.

[3] 郭裕湘. 基于公共管理主义视野的我国高校学术管理机制创 新 $[\mathrm{J}]$. 中国成人教育,2016(18):38-41

[4] 白璐. 教育管理主义的论述 $[\mathrm{J}]$. 高教学刊, 2016 (06): 167 -168 . 